\title{
ПРОГНОЗИРОВАНИЕ КОЭФФИЦИЕНТА ПРОДУКТИВНОСТИ СКВАЖИН С БОКОВЫМ СТВОЛОМ (НА ПРИМЕРЕ УНЬВИНСКОГО МЕСТОРОЖДЕНИЯ)
}

\author{
щербаков Александр Анатольевич',
}

aleksandr.a.shcherbakov@gmail.com

\author{
Хижняк Григорий Петрович', \\ xgp@mail.ru \\ Галкин Владислав Игнатьевич', \\ vgalkin@pstu.ru
1 Пермский национальный исследовательский политехнический университет, Россия, 614990, г. Пермь, Комсомольский пр., 29.

\begin{abstract}
Актуальность. Многие месторождения Соликамской депрессии Пермского края характеризуются завершающей стадией разработки и имеют высокий коэффициент извлечения нефти, близкий к проектному, высокую обводненность добываемой продукции, ухудшение технико-экономических показателей добычи. Для выполнения проектных показателей на месторождениях применяются различные методы повышения нефтеотдачи. Анализ их применения показывает, что наибольший средний прирост начального дебита скважин по нефти достигается путем зарезки боковых стволов. При обосновании расположения бокового ствола в интервале продуктивного пласта одним из основных показателей дальнейшей эффективности работы скважины является начальный коэффициент продуктивности скважины по нефти.

Цель: разработать методику прогнозирования коэффициента продуктивности по нефти скважин с боковым стволом с учетом геолого-технологических характеристик объекта.

объекты: бобриковские терригенные отложения Уньвинского месторождения Соликамской депрессии.

Методы: корреляционный и регрессионный анализ, основанный на данных геофизических и гидродинамических исследований скважин, значениях фильтрационно-емкостных свойств пласта, физико-химических свойств нефти, а также геолого-технологических показателях.

Результаты. Разработанная методика позволяет оценивать значения коэффициента продуктивности по нефти скважин с боковым стволом на основе результатов геофизических и гидродинамических исследований скважин, значений фильтрационно-емкостных свойств пласта, физико-химических свойств нефти, а также геолого-технологических показателей с помощью пошагового регрессионного анализа и разделения исходных данных значений коэффициента продуктивности по нефти на классы на ос-

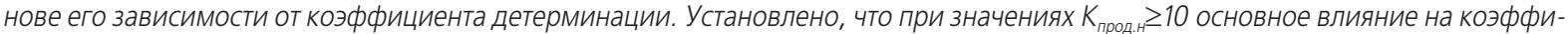
циент продуктивности по нефти скважин с боковыми стволами оказывают технологические показатели - зенитный угол $\alpha$ бокового ствола в интервале продуктивного пласта и длина $L_{c т}$ ствола скважины в пласте, что говорит о возможности регулирования процесса довыработки запасов нефти изменением этих параметров.
\end{abstract}

\section{Ключевые слова:}

Боковые стволы, повышение нефтеотдачи пласта, коэффициент продуктивности по нефти, корреляционный анализ, регрессионный анализ.

Значительная часть месторождений на территории Соликамской депрессии находится или вступает в завершающую стадию разработки. Для выполнения проектных показателей на месторождениях применяются методы повышения нефтеотдачи (ПНП) - гидравлический разрыв пласта (ГРП), зарезка боковых стволов (ЗБС), радиальное бурение (РБ), соляно-кислотные обработки (СКО) призабойной зоны пласта [1-13]. Анализируя применение методов ПНП на этих месторождениях в 2010-2018 гг. (726 операций), можно отметить снижение со временем прироста начального дебита скважин по нефти после ПНП (рис. 1), что связано с существенной выработкой извлекаемых запасов нефти.

Наибольший средний прирост начального дебита скважин по нефти 13 т/сут достигается ЗБС при среднем по всем методам 9,5 т/сут. ЗБС позволяет охватить разработкой остаточные запасы углеводородов, избежать строительства новых скважин и, как следствие, обустройства новых выкидных линий и промысловых трубопроводов.

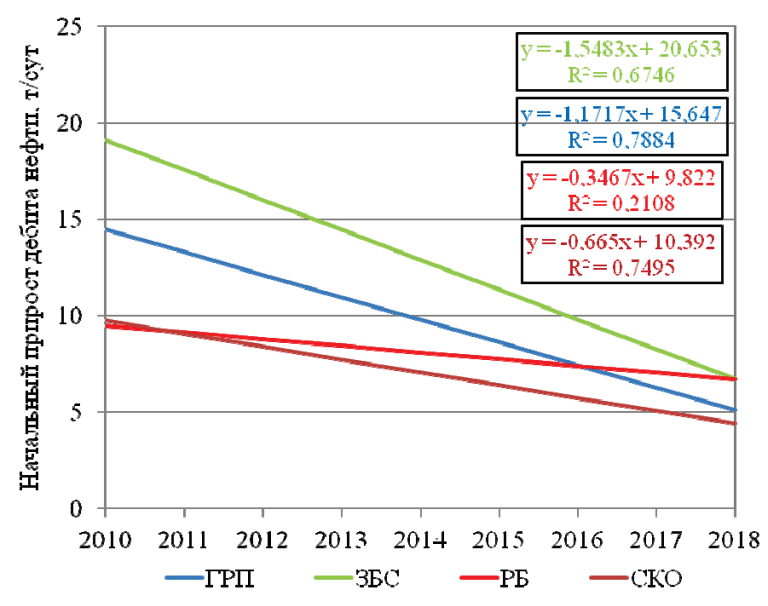

Puс. 1. Средний начальный прирост дебита по нефти в скважинах месторождений Соликамской депрессии

Fig. 1. Average initial increase in oil production rate in wells of the Solikamskaya depression fields 
ЗБС активно применяется на месторождениях Соликамской депрессии. В 2010-2018 гг. в добывающих скважинах проведено 165 операций, из которых основная часть - $80 \%$ - в терригенных тульских и бобриковских залежах (табл. 1), из них 30 \% приходится на Уньвинское месторождение.

Таблииа 1. Показатели ЗБС на месторождениях Соликамской депрессии

Table 1. Sidetracking in wells of the Solikamskaya depression fields

\begin{tabular}{|c|c|c|c|c|c|c|c|c|c|c|}
\hline $\begin{array}{c}\text { Показатель } \\
\text { Parameter }\end{array}$ & 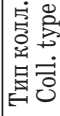 & 2010 & 2011 & 2012 & 2013 & 2014 & 2015 & 2016 & 2017 & 2018 \\
\hline \multirow{2}{*}{$\begin{array}{l}\text { Количество } \\
\text { ЗБС, скв. } \\
\text { Sidetracking } \\
\text { number, wells }\end{array}$} & 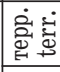 & 13 & 27 & 32 & 19 & 19 & 7 & 8 & 4 & 2 \\
\hline & 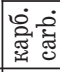 & 3 & 1 & 7 & 4 & 2 & 9 & 4 & 4 & 0 \\
\hline \multirow{2}{*}{$\begin{array}{l}\text { Средний на- } \\
\text { чальный де- } \\
\text { бит скважи- } \\
\text { ны по нефти } \\
\text { после ЗБС, } \\
\text { т/сут } \\
\text { Average initi- } \\
\text { al oil produc- } \\
\text { tion rate af- } \\
\text { ter sidetrac- } \\
\text { king, t/day }\end{array}$} & 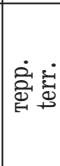 & 23,8 & 17,7 & 15,1 & 14,4 & \begin{tabular}{|l|l}
8,2 \\
\end{tabular} & 9,8 & 8,5 & 5,6 & 11,5 \\
\hline & 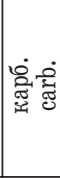 & 13,6 & 15,4 & 9,9 & 32,6 & 13,4 & 10,8 & 7,2 & 8,2 & 0 \\
\hline
\end{tabular}

Все ЗБС проводились на фонде скважин, выведенных из эксплуатации.

Начальный дебит по нефти после ЗБС с каждым годом снижается. Так, в 2010 г. в терригенных коллекторах начальный дебит составлял в среднем 23,8 т/сут, к 2017 г. снизился до 5,6 т/сут.

Задача прогноза начального дебита скважины является актуальной, ей посвящен ряд работ [14-20]. Так, в [14] предложено уравнение для прогноза дебитов новых скважин на территории Предуральского краевого прогиба:

$$
q_{\text {ж0 }}=A+A_{P} P_{\text {пил }} / P_{\text {нас }}+A_{\mu} \mu_{\mathrm{H}}+A_{h} h+A_{K \pi} K_{\text {пI }}+A_{k} k+A_{j} k / \mu_{\mathrm{H}},
$$

где $A, A_{p}, A_{\mu}, A_{h}, A_{K n}, A_{k}, A_{j}$ - коэффициенты, определяемые для конкретных геолого-технологических условий разработки (табл. 2); $P_{\text {пл }}$ - пластовое давление, МПа; $P_{\text {нас }}$ - давление насыщения, МПа; $\mu_{\text {н }}$ - динамическая вязкость нефти, мПа'с; $h$ - толщина пласта, м; $K_{\text {п }}$ - пористость, $\%$; $k$ - проницаемость, мкм².

Таблица 2. Коэффициенты уравнения (1) по отложениям Table 2. Coefficients of equation (1) by deposits

\begin{tabular}{|l|c|c|c|c|c|c|c|}
\hline \multicolumn{1}{|c|}{ Отложения/Deposits } & $A$ & $A_{p}$ & $A_{\mu}$ & $A_{h}$ & $A_{K \Pi} / A_{\phi}$ & $A_{k}$ & $A_{j}$ \\
\hline Башкирские/Bashkir & 2,2 & 11,8 & $-2,5$ & 0,57 & 0,83 & 0 & 0 \\
\hline Визейские/Visean & 25,6 & 0 & 0 & 0,8 & 0 & 0 & 0,016 \\
\hline $\begin{array}{l}\text { Tyрнейско-фаменские } \\
\text { Tournaisian and Famennian }\end{array}$ & 16 & 0 & $-2,4$ & 1,79 & 0,83 & 0 & 0 \\
\hline
\end{tabular}

Однако ввиду существенного роста выработки запасов нефти и увеличения доли трудноизвлекаемых запасов с 2011 г. значения начальных фактических дебитов значительно ниже рассчитываемых по уравнению (1).
При обосновании расположения бокового ствола в интервале продуктивного пласта одним из основных показателей дальнейшей эффективности работы скважины является начальный коэффициент продуктивности скважины по нефти $\left(K_{\text {прод.н }}\right)$. В работе для прогнозной оценки $K_{\text {прод.н использова- }}$ ны данные по ЗБС в бобриковских терригенных отложениях 40 скважин Уньвинского месторождения. Исходной информацией послужили результаты геофизических и гидродинамических исследований, значения фильтрационно-емкостных свойств пласта, физико-химические свойства нефти, а также геолого-технологические показатели, по которым формируется исходная выборка.

При анализе исследовались следующие параметры: толщина пласта $h_{\text {пл }}$, ; эффективная нефтенасыщенная толщина $h_{\text {эр.н }}$, м; количество пропластков $N_{\text {пропл}}$, шт; пористость $K_{\text {п }}, \%$; проницаемость по

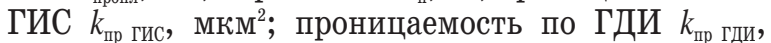
мкм $^{2}$; плотность запасов $\rho_{\text {зап, }}$ т $/ \mathrm{M}^{2}$; текущая нефтенасыщенность $K_{\text {н }}, \%$; динамическая вязкость $\mu$, мПа॰с; плотность $\rho$, т/ $\mathrm{M}^{3} ;$ зенитный угол бокового ствола в интервале продуктивного пласта $\alpha$, град; длина ствола скважины в пласте $L_{c \text { r. }}$ м; расстояние до забоя ближайшей нагнетательной скважины $L_{\text {н }}$, м; расстояние до забоя ближайшей добывающей скважины $L_{\Perp}$, м.

Для всех параметров исходной выборки построены корреляционные поля (табл. 3) [21-23]. Анализ данных полей в совокупности со значениями коэффициента корреляции $(r)$ показал степень влияния параметров на коэффициент продуктивности скважин по нефти.

Таблица 3. Корреляиионная матрица для выборки бобриковских терригенных отложений Уньвинского месторождения

Table 3. Correlation matrix for a sample of Bobrikovskiy terrigenous deposits of the Unvinskoe field

\begin{tabular}{|c|c|c|c|c|c|c|c|c|}
\hline $\begin{array}{l}\text { Параметр } \\
\text { Parameter }\end{array}$ & $\begin{array}{r}h_{\text {эф.H }} \\
h_{\text {effthick }}\end{array}$ & $\begin{array}{c}k_{\text {пр гди }} \\
k_{W T}\end{array}$ & $\begin{array}{l}\rho_{\text {зап }} \\
\rho_{\text {res }}\end{array}$ & $\ldots$ & $\begin{array}{l}K_{\mathrm{H}} \\
S_{0}\end{array}$ & $\alpha$ & $\begin{array}{l}L_{\mathrm{cr}} \\
L_{b}\end{array}$ & $\begin{array}{c}K_{\text {прод.Н. }} \\
J_{0}\end{array}$ \\
\hline $\begin{array}{c}h_{\text {эф.н }} \\
h_{\text {ef.thick }}\end{array}$ & 1,00 & $\frac{0,19}{0,247}$ & $\underline{0,54}$ & $\ldots$ & $\frac{0,37}{0,017}$ & $\frac{0,40}{0,010}$ & $\frac{0,38}{0,017}$ & $\frac{0,50}{0,001}$ \\
\hline $\begin{array}{c}k_{\text {пр гди }} \\
k_{W T}\end{array}$ & & 1,00 & $\begin{array}{c}0,34 \\
0,034\end{array}$ & $\ldots$ & $\begin{array}{r}\underline{0,39} \\
\underline{0,014} \\
\end{array}$ & $\begin{array}{r}0,63 \\
\underline{0,000} \\
\end{array}$ & $\begin{array}{l}\underline{0,61} \\
\underline{0,000} \\
\end{array}$ & $\frac{0,72}{0,000}$ \\
\hline $\begin{array}{l}\rho_{\text {зап }} \\
\rho_{\text {res }}\end{array}$ & & & 1,00 & ... & $\underline{0,56}$ & $\frac{0,40}{0,010}$ & $\underline{0,47}$ & $\underline{0,54}$ \\
\hline$\cdots$ & $\cdots$ & $\cdots$ & $\cdots$ & $\ldots$ & $\cdots$ & 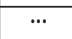 & $\ldots$ & $\cdots$ \\
\hline $\begin{array}{l}K_{\text {H }} \\
S_{o}\end{array}$ & & & & $\ldots$ & 1,00 & $\frac{0,66}{0,000}$ & $\frac{0,60}{0,000}$ & $\underline{0,71}$ \\
\hline$\alpha$ & & & & $\ldots$ & & 1,00 & $\underline{0,77}$ & $\frac{0,75}{0,000}$ \\
\hline $\begin{array}{l}L_{\text {cr }} \\
L_{b}\end{array}$ & & & & $\cdots$ & & & 1,00 & $\frac{0,73}{0,000}$ \\
\hline
\end{tabular}

Примечание: в числителе - значение коэффициента корреляиии $r$, в знаменателе - уровень статистической значимости $p$. При $p<0,05$ (выделены красным иветом) корреляционные связи статистически значимы.

Note: the correlation coefficient $r$ value is in the numerator, the statistical significance level $p$ is in the denominator. The correlation relationships are statistically significant at $p<0,05$ (in red).

Из корреляционной матрицы видно наличие статистически значимых корреляционных связей 
коэффициента продуктивности с параметрами $\alpha$, $L_{\text {сг }}, k_{\text {пр гди }}, K_{\text {н }}, \rho_{\text {зап }}, h_{\text {эф.н }}, K_{\text {пा }}, k_{\text {пр гис }}, L_{\text {н }}, h_{\text {плл }}, L_{\text {д }}$.

По всем значениям выборки с использованием пошагового регрессионного анализа строится многомерное уравнение регрессии, в котором в качестве зависимой переменной использовалось значение коэффициента продуктивности $K_{\text {прод.н }}$, а независимыми - остальные параметры выборки:

$K_{\text {прод.н }}^{\mathrm{M}}=-24,17+0,04 \alpha+31,24 k_{\text {пр гди }}+$ $+0,25 K_{\text {н }}+0,38 h_{\text {эф.н }}-0,35 N_{\text {пропл }}+0,11 L_{\text {ст }}$,

при $R^{2}=0,84, F=27,83, F_{\text {к }}=6,33$, где $R^{2}-$ коэффициент детерминации, $F$ - критерий Фишера, $F_{\text {к }}$ критическое значение критерия Фишера.

Формирование очередности включения показателей в уравнение регрессии происходило в последовательности, приведенной в (2). На первом шаге формирования уравнения был включен показатель $\alpha$ при $r=0,75, R^{2}=0,56$. С добавлением следующего показателя на каждом последующем шаге коэффициент детерминации $R^{2}$ увеличивался 0,$67 ; 0,75 ; 0,8 ; 0,82 ; 0,84$.

Сопоставление фактических $\left(K_{\text {прод.н }}^{\Phi}\right)$ и рассчитанных по уравнению (2) модельных значений коэффициента продуктивности $\left(K_{\text {прол.н }}^{\mathrm{M}}\right)$ свидетельствует о значительном разбросе данных (рис. 2). Абсолютная погрешность $\Delta_{\text {абс }}^{\mathrm{c}}$ составила 1,4 т/(сут·МПа), относительная $\Delta_{\text {отн }}^{\mathrm{c}}-23,6 \%$.

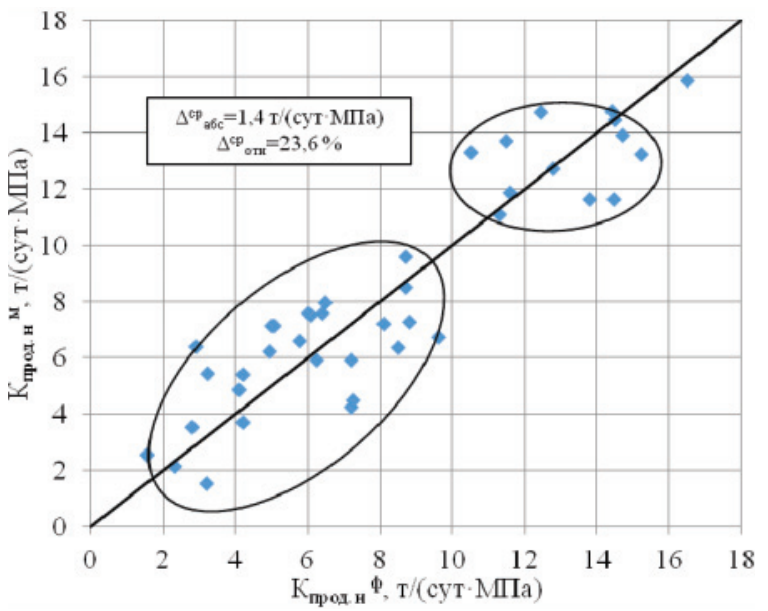

Pис. 2. Сопоставление модельных и фактических значений $K_{\text {прод.н }}$

Fig. 2. Comparison of oil productivity ratio model and actual values

Анализ корреляционного поля показал, что оно состоит из двух подчастей (классов). При значениях $K_{\text {прод.н }}<10$ модельные и фактические значения коэффициента продуктивности достаточно хорошо контролируют друг друга, при $K_{\text {прод.н }} \geq 10$ наблюдается существенный разброс данных: значения $K_{\text {прод.н }}^{\Phi}$ находятся в диапазоне 10-17 т/(сут·МПа), тогда как модельные - только в интервале 11-15. Исходя из этого сделано предположение о том, что на значения $K_{\text {прод.н }}$ в пределах этих классов действуют различные показатели. Для подтверждения этого предположения выполнен пошаговый регрессионный анализ выборки следующим образом:
- данные выборки были ранжированы по значению $K_{\text {прод.н }}$ от минимального к максимальному;

- построено многомерное уравнение регрессии по первым трем $(N=3)$ значениям выборки (табл. 4). Затем уравнение строится по первым четырем $(N=4)$ значениям, по первым пяти $(N=5)$ значениям и так далее до $N=40$.

Использование данного подхода позволило проследить в динамике влияние показателей на $K_{\text {прод.н }}$ во всем диапазоне его изменения.

Таблица 4. Коэффициенты в многомерных уравнениях при пошаговом регрессионном анализе данных бобриковских терригенных отложений Уньвинского месторождения

Table 4. Coefficients in multidimensional equations with step-bystep regression analysis of data from Bobrikovskie terrigenous deposits of the Unvinskoye field

\begin{tabular}{|c|c|c|c|c|c|c|c|c|c|}
\hline $\mathrm{N}$ & $\begin{array}{c}\text { Свободный член } \\
\text { Absolute term }\end{array}$ & $\begin{array}{c}h_{\text {эф.н }} \\
h_{\text {ef.thick }}\end{array}$ & $\begin{array}{c}k_{\text {пр гди }} \\
k_{\text {}}\end{array}$ & $\begin{array}{c}\rho_{\text {зап }} \\
\rho_{\text {res }}\end{array}$ & $\cdots$ & $\begin{array}{c}K_{\text {н }} \\
S_{o}\end{array}$ & $\alpha$ & $\begin{array}{c}L_{\text {ст }} \\
L_{b}\end{array}$ & $R^{2}$ \\
\hline 3 & $-8,873$ & & & & $\cdots$ & & & 0,456 & 0,994 \\
\hline 4 & 0,121 & 0,008 & & & $\cdots$ & & & & 1 \\
\hline$\cdots$ & $\cdots$ & $\cdots$ & $\cdots$ & $\cdots$ & $\cdots$ & $\cdots$ & $\cdots$ & $\cdots$ & $\cdots$ \\
\hline 37 & $-168,47$ & 0,318 & 30,99 & 1,375 & $\cdots$ & 0,238 & & 0,14 & 0,821 \\
\hline 38 & $-169,031$ & 0,308 & 30,63 & 1,382 & $\cdots$ & 0,233 & & 0,148 & 0,835 \\
\hline 39 & $-23,8$ & 0,384 & 30,32 & & $\cdots$ & 0,248 & 0,045 & 0,099 & 0,818 \\
\hline 40 & $-24,17$ & 0,38 & 31,24 & & $\cdots$ & 0,25 & 0,04 & 0,11 & 0,835 \\
\hline
\end{tabular}

Изменение коэффициента детерминации $R^{2}$ полученных уравнений представлено на рис. 3. До $N=27$ значения $R^{2}$ имеют тенденцию к уменьшению и при этом характеризуются значительным разбросом. Для $N>28$ наблюдается последовательное, без резких скачков, увеличение значений $R^{2}$ (рис. $3, a)$, при этом анализ построенных многомерных уравнений регрессии показывает, что формирование моделей начинается с технологических показателей $\alpha, L_{\text {сг }}$, тогда как до $N=27$ на первых местах преобладали геологические показатели. Таким образом, предположение о необходимости разделения исходной выборки на два класса по значению $K_{\text {прод.н }}=10$ подтвердилось (рис. 2,3, б).

Для каждого класса в отдельности получены следующие регрессионные уравнения:

$$
\begin{gathered}
\cdot 1 \text { класс }\left(K_{\text {прод.н }}<10\right) \\
K_{\text {прод.н }}^{\mathrm{M}}=-18,777+0,233 K_{\text {н }}+0,136 N_{\text {пропл }}+ \\
+18,149 k_{\text {пр гди }}+0,994 \rho_{\text {зап }}, \\
R^{2}=0,53, F=6,27, F_{\mathrm{\kappa}}=4,22 ; \\
\cdot 2 \text { класс }\left(K_{\text {прод.н }} \geq 10\right) \\
K_{\text {прод.н }}^{\mathrm{M}}=18,057-0,013 L_{\text {д }}+0,057 K_{1 \mathrm{H}}+0,186 L_{\text {ст }}- \\
-0,177 h_{\text {пл }}-2,868 \rho_{\text {зап }}+3,579 \mu-0,127 \alpha, \\
R^{2}=0,88, F=8,01, F_{\mathrm{K}}=7,51 .
\end{gathered}
$$

Сопоставление модельных значений коэффициента продуктивности, рассчитанных по уравнениям (3) и (4) для выделенных классов, с фактическими значениями, свидетельствует об увеличении точности прогноза коэффициента продуктивности (рис. 4).

Абсолютная погрешность составила 0,9 т/(сут·МПа), относительная - 17,3\%. Полу- 
ченное по сравнению с уравнением (2) (рис. 2) снижение абсолютной (на 0,5 т/(сут·МПа)) и относительной (на 6,3 \%) погрешностей говорит о возможности выделения классов в исходной выборке данных при применении пошагового регрессионного анализа для прогноза коэффициента продуктивности по нефти скважин с боковыми стволами.
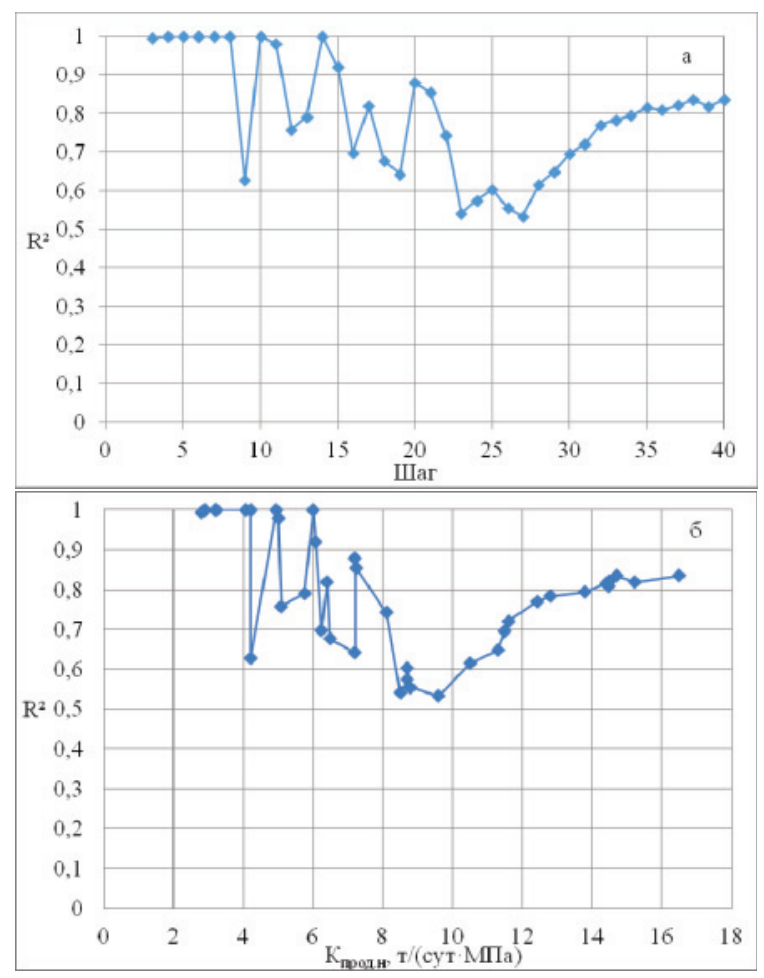

Pис.3. Изленение коэффициента детерлинации: а) по шагам, б) по коэффициенту продуктивности

Fig. 3. Change in determination coefficient: a) step-by-step, б) by the productivity index

Таким образом, разработанная методика позволяет оценивать значения коэффициента продуктивности по нефти скважин с боковым стволом на основе результатов геофизических и гидродинамических исследований скважин, значений фильтрационно-емкостных свойств пласта, физико-химических свойств нефти, а также геолого-технологических показателей с помощью пошагового регрессионного анализа и разделения исходных данных

\section{СПИСОК ЛИТЕРАТУРЫ}

1. Анализ проведения геолого-технических мероприятий по увеличению продуктивности добывающих скважин на нефтяных месторождениях Пермского края / П.Ю. Илюшин, Р.М. Рахимзянов, Д.Ю. Соловьев, И.Ю. Колычев // Вестник Пермского национального исследовательского политехнического университета. Геология. Нефтегазовое и горное дело. - 2015. № 15. - C. 81-89. DOI: 10.15593/2224-9923/2015.15.9.

2. Щербаков А.А., Турбаков М.С., Дворецкас Р.В. Анализ эффективности применения методов увеличения нефтеотдачи месторождений Пермского Прикамья с трудноизвлекаемыми запасами // Нефтяное хозяйство. - 2012. - № 12. - С. 97-99. значений коэффициента продуктивности по нефти на классы на основе его зависимости от коэффициента детерминации.

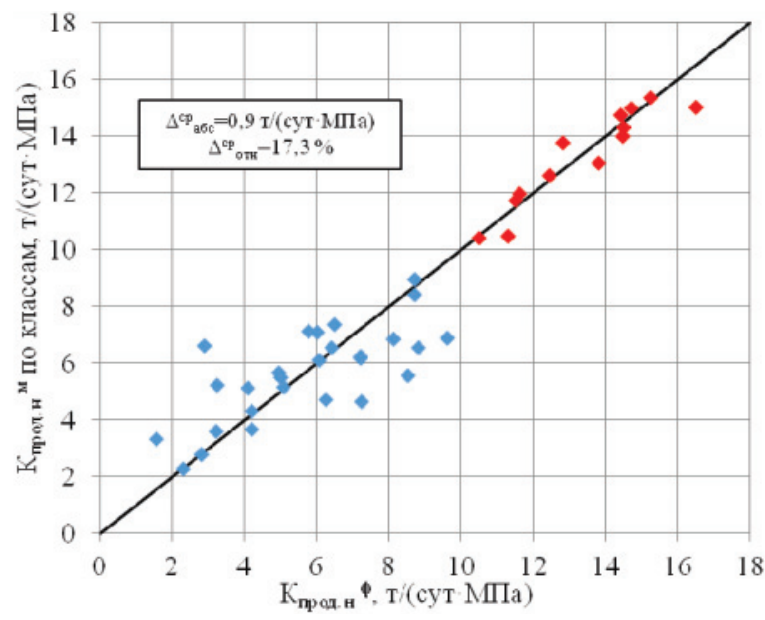

Puс.4. Сопоставление фактических и модельных значений коэффициента продуктивности по нефти, рассчитанных по уравнениям (3) и (4) для выделенных классов (синий-1 класс, красный-2 класс)

Fig. 4. Comparison of the oil productivity index actual and model values, calculated according to equations (3) and (4) for the selected classes (blue $-1^{\text {st }}$ class, red $-2^{\text {nd }}$ class)

Таким образом, разработанная методика позволяет оценивать значения коэффициента продуктивности по нефти скважин с боковым стволом на основе результатов геофизических и гидродинамических исследований скважин, значений фильтрационно-емкостных свойств пласта, физико-химических свойств нефти, а также геолого-технологических показателей с помощью пошагового регрессионного анализа и разделения исходных данных значений коэффициента продуктивности по нефти на классы на основе его зависимости от коэффициента детерминации.

Установлено, что при значениях $K_{\text {прон.н }} \geq 10$ основное влияние на коэффициент продуктивности по нефти скважин с боковыми стволами оказывают технологические показатели - зенитный угол $\alpha$ бокового ствола в интервале продуктивного пласта и длина $L_{\text {ст }}$ ствола скважины в пласте, что говорит о возможности регулирования процесса довыработки запасов нефти изменением этих параметров.

3. Turbakov M., Shcherbakov A. Determination of enhanced oil recovery candidate fields in the Volga-Ural oil and gas region territory // Energies. - 2015. - № 8. - P. 20-23.

4. Кузьмина Т.А., Миронов А.Д. Опыт разработки низкопродуктивных объектов с применением технологии многозабойного бурения // Вестник Пермского национального исследовательского политехнического университета. Геология. Нефтегазовое и горное дело. - 2012. - № 3. - С. 89-93.

5. Стрижов И.Н., Кочкин С.Е., Ибатуллин Т.Р. Влияние методов интенсификации притока на динамику добычи нефти // Нефтяное хозяйство, - 2003. - № 9. - С. 65-67.

6. Дмитриев А.Ю., Чубик П.С., Абакумов Л.Б. Методика оценки возможности и целесообразности восстановления бездейству- 
ющих скважин бурением из них дополнительных стволов // Нефтегазопромысловое дело. - 1997. - № 10-11. - С. 13-17.

7. Котенев Ю.А., Андреев В.Е., Ягафаров Ю.Н. Геология и разработка нефтяных месторождений Ишимбайского Приуралья с применением методов увеличения нефтеотдачи. - Уфа: УГНTУ, 2004. - 252 c.

8. Крянев Д.Ю., Жданов С.А. Применение методов увеличения нефтеотдачи пластов в России и за рубежом. Опыт и перспективы // Бурение и нефть. - 2011. - № 2. - С. 22-26.

9. Хисамутдинов Н.И., Тахаутдинов Ш.Ф., Телин А.Г. Проблемы извлечения остаточной нефти физико-химическими методами: монография. - М.: ОАО «ВНИИОЭНГ», 2001. - 181 с.

10. Economides M.J., Nolte K.G. Reservoir Stimulation. - Eglewood Cliffs, New Jersey: Prentice Hall, 1989. - 430 p.

11. Smith C.R. Mechanics of secondary oil recovery. - Reinhold Publ. Corp., 1966. - $504 \mathrm{p}$.

12. Исследование воздействия кислотогенерирующего состава на керны продуктивных отложений Куюмбинского лицензионного участка / Г.П. Хижняк, А.М. Амиров, Е.А. Гладких, В.А. Колесов, А.Г. Захарян, А.Е. Чикин, Р. Харрис // Нефтяное хозяйство. -2015 . - № 3. - С. 31-35.

13. Bahadori A. Fundamentals of Enhanced Oil and Gas Recovery from Conventional and Unconventional Reservoirs. - US: Gulf Professional Publishing, 2018. $-536 \mathrm{p}$.

14. Поплыгин В.В., Галкин С.В. Прогнозная экспресс-оценка показателей разработки нефтяных залежей // Нефтяное хозяйство. - 2011. - № 3. - С. 112-115.

15. Кривощеков С.Н., Рябоконь Е.П. Статистическое моделирование дебита скважины с боковым стволом на месторождениях Верхнего Прикамья // Нефтепромысловое дело. - 2017. № 11. - C. $39-44$.

16. Галкин В.И., Репина В.А. Разработка статистической модели прогнозирования дебита нефти на примере пласта Тл2а одного из месторождений башкирского свода // Нефтяное хозяйство. - 2015. - № 11. - С. 111-113.

17. Репина В.А. Прогнозирование значения дебита нефти по данным трехмерной фильтрационной модели // Проблемы разработки месторождений углеводородных и рудных полезных ископаемых. - 2014. - № 1. - С. 63-66.

18. Azadeh A., Pourebrahim Ahvazi M., Motevali Haghighi S. An intelligent algorithm for determination and optimization of productivity factors in upstream oil projects / Journal of Petroleum Science and Engineering. - 2018. - № 167. - C. 375-395. DOI: 10.1016/j.petrol.2018.03.099.

19. Productivity evaluation and influential factor analysis for Sarvak reservoir in South Azadegan oil field, Iran / H. Liu, R. Guo, J. Dong, L. Liu, Y. Liu, Y. Yi // Petroleum Exploration and Development. - 2013. - V. 40. - № 5. - P. 627-634. DOI: 10.1016/S1876-3804(13)60082-8.

20. New methodology to quantify productivity of vertical wells in naturally fractured solution gas drive reservoirs with dual porosity and dual permeability / Z. Tariq, S. Al-Nuaim, A. Abdulraheem, M.R. Khan // Society of Petroleum Engineers - PAPG/SPE Pakistan Section Annual Technical Conference and Exhibition. 2016. - C. $139-155$.

21. Ott R.L., Longnecker M. An Introduction to Statistical Methods and Data Analysis. 7 ed. - Boston: Cengage Learning, 2016. $1296 \mathrm{p}$.

22. Montgomery D.C., Peck E.A. Introduction to linear regression analysis. - New York: John Wiley \& Sons, 1982. - 504 p.

23. Afifi A., May S., Clark V.A. Practical multivariate analysis. 5 ed. - UK: Chapman and Hall/CRC, 2011. - 537 p.

Поступила 26.02.2019 2.

\section{Информация об авторах}

Щербаков A.A., старший преподаватель кафедры нефтегазовых технологий Пермского национального исследовательского политехнического университета.

Хижняк Г.П., доктор технических наук, доцент, заведующий кафедрой нефтегазовых технологий Пермского национального исследовательского политехнического университета.

Галкин В.И., доктор геолого-минералогических наук, профессор, заведующий кафедрой геологии нефти и газа Пермского национального исследовательского политехнического университета. 
UDC 622.276 .346

\title{
PREDICTION OF SIDETRACK WELLS PRODUCTIVITY INDEX (ON EXAMPLE OF THE UNVINSKOE FIELD)
}

\author{
Aleksandr A. Shcherbakov', \\ aleksandr.a.shcherbakov@gmail.com \\ Grigory P. Khizhnyak', \\ xgp@mail.ru \\ Vladislav I. Galkin', \\ vgalkin@pstu.ru \\ 1 Perm National Research Polytechnic University, \\ 29, Komsomolskiy avenue, Perm, Russia, 614990.
}

Relevance. Many fields of the Solikamskaya depression of the Perm Krai are characterized by the final stage of development and have a high oil recovery rate, close to the project, high water cut, declining technical and economic production indicators. To achieve the project indicators at the fields, various methods of enhanced oil recovery are used. The analysis of their application shows that the greatest average increase in the initial oil production is achieved by sidetracking. When justifying the location of the sidetrack wellbore in the interval of the productive layer, one of the main indicators of further well performance is the initial oil productivity index of the well.

The main aim of the research is to develop a methodology for predicting the oil productivity index for sidetracks, taking into account geological and technological characteristics of the object.

Objects: Bobrikovskie terrigenous deposits of the Unvinskoye field of the Solikamskaya depression.

Methods: correlation and regression analysis based on the data of geophysical and hydrodynamic well studies, reservoir properties, physical and chemical oil properties, as well as geological and technological indicators.

Results. The developed method allows estimating the values of oil productivity index for sidetracks based on the results of geophysical and hydrodynamic well studies, reservoir properties, physical and chemical oil properties, as well as geological and technological indicators using step-by-step regression analysis and oil productivity data values division into classes based on its dependence on the coefficient of determination. It was established that for $\$ 10$ values the technological indicators - zenith angle $\alpha$ of the sidetrack in the reservoir interval and the length $L_{b}$ of the borehole in the reservoir - affect most of all the oil productivity, which indicates the possibility of controlling oil recovery by changing these parameters.

Key words:

Sidetracks, enhanced oil recovery, oil productivity factor, correlation analysis, regression analysis.

\section{REFERENCES}

1. Ilyushin P.Yu., Rakhimzyanov R.M., Solovev D.Yu., Kolychev Y.Iu. Analysis of well intervention aimed at oil production enhancement in the Perm krai's fields. Bulletin of PNRPU. Geology. Oil \& Gas Engineering \& Mining, 2015, no. 15, pp. 81-89. In Rus. DOI: $10.15593 / 2224-9923 / 2015.15 .9$

2. Shcherbakov A.A., Turbakov M.S., Dvoretskas R.V. Effectiveness analysis of enhanced oil recovery methods implementation for hard-to-recover oil reserves of Perm Kama region. Oil industry, 2012, no. 12, pp. 97-99. In Rus.

3. Turbakov M., Shcherbakov A. Determination of enhanced oil recovery candidate fields in the Volga-Ural oil and gas region territory. Energies, 2015, no. 8, pp. 20-23.

4. Kuzmina T.A., Mironov A.D. Experience in the development of objects unproductive using technology multihole drilling. Bulletin of PNRPU. Geology. Oil and Gas Engineering and Mining, 2012, no. 3, pp. 89-93. In Rus.

5. Strizhov I.N., Kochkin S.E., Ibatullin T.R. Inflow intensification methods effect on performance of an oil recovery. Oil industry, 2003, no. 9, pp. 65-67. In Rus.

6. Dmitriev A.Yu., Chubik P.S., Abakumov L.B. Methods for assessing the feasibility of restoring inactive wells by drilling additional boreholes from them. Oilfield engineering, 1997, no. 10-11, pp. 13-17. In Rus.

7. Kotenev Yu.A., Andreev V.E., Yagafarov Yu.N. Geologiya i razrabotka neftyanykh mestorozhdeniy Ishimbayskogo Priuralya s primeneniem metodov uvelicheniya nefteotdachi [Geology and development of oil fields of the Ishimbay Priuralie using enhanced oil recovery methods]. Ufa, UGNTU Publ., 2004. 252 p.
8. Kryanev D., Zhdanov S. Use of advanced reservoir recovery methods in Russia and abroad. Drilling and Oil, 2011, no. 2, pp. 22-26. In Rus.

9. Khisamutdinov N.I., Takhautdinov Sh.F., Telin A.G. Problemy izvlecheniya ostatochnoy nefti fiziko-khimicheskimi metodami: monografiya [Problems of residual oil recovery by physicochemical methods: monograph]. Moscow, LLC VNIIOENG Publ., 2001. $181 \mathrm{p}$.

10. Economides M.J., Nolte K.G. Reservoir Stimulation. Eglewood Cliffs, Prentice Hall, 1989. 430 p.

11. Smith C.R. Mechanics of secondary oil recovery. Reinhold Publ. Corp., 1966. 504 p.

12. Khizhnyak G.P., Amirov A.M., Gladkikh E.A., Kolesov V.A., Zakharyan A.G., Chikin A.E., Kharris R. Study of the acid-generating composition effect on the cores of the productive deposits of the Kuyumbinskiy license area. Oil industry, 2015, no. 3, pp. 31-35. In Rus.

13. Bahadori A. Fundamentals of Enhanced Oil and Gas Recovery from Conventional and Unconventional Reservoirs. US, Gulf Professional Publ., 2018. 536 p.

14. Poplygin V.V., Galkin S.V. Forecast quick evaluation of the indices of the development of the oil deposits. Oil industry, 2011, no. 3, pp. 112-115. In Rus.

15. Krivoshchekov S.N., Ryabokon E.P Statistical modeling of the flow-rate of a sidetracked well at the fields of the Upper Kama region. Oilfield engineering, 2017, no. 11, pp. 39-44. In Rus.

16. Galkin V.I., Repina V.A. Development of the statistical forecasting model of oil production rate (case study of oil reservoir formation Tl2a one of the oil field of the Bashkir arch). Oil industry, 2015, no. 11, pp. 111-113. In Rus. 
17. Repina V.A. Prognozirovanie znacheniya debita nefti po dannym trekhmernoy filtratsionnoy modeli [Forecasting the value of oil flow rate according to the three-dimensional filtration model]. Problems of development of hydrocarbon and ore mineral deposits, 2014, no. 1, pp. 63-66. In Rus.

18. Azadeh A., Pourebrahim Ahvazi M., Motevali Haghighi S. An intelligent algorithm for determination and optimization of productivity factors in upstream oil projects. Journal of Petroleum Science and Engineering, 2018, no. 167, pp. 375-395. D0I: 10.1016/j.petrol.2018.03.099

19. Liu H., Guo R., Dong J., Liu L., Liu Y., Yi Y. Productivity evaluation and influential factor analysis for Sarvak reservoir in South Azadegan oil field, Iran. Petroleum Exploration and Development, 2013, vol. 40, no. 5, pp. 627-634. DOI: $10.1016 / \mathrm{S} 1876-3804(13) 60082-8$.
20. Tariq Z., Al-Nuaim S., Abdulraheem A., Khan M.R. New methodology to quantify productivity of vertical wells in naturally fractured solution gas drive reservoirs with dual porosity and dual permeability. Society of Petroleum Engineers - PAPG/SPE Pakistan Section Annual Technical Conference and Exhibition, 2016. pp. $139-155$.

21. Ott R.L., Longnecker M. An Introduction to Statistical Methods and Data Analysis. 7 ed. Boston, Cengage Learning, 2016. $1296 \mathrm{p}$.

22. Montgomery D.C., Peck E.A. Introduction to linear regression analysis. New York, John Wiley \& Sons Publ., 1982. 504 p.

23. Afifi A., May S., Clark V.A. Practical multivariate analysis. 5 ed. UK, Chapman and Hall/CRC Publ., 2011. 537 p.

Received: 26 February 2019.

\section{Information about the authors}

Aleksandr A. Shcherbakov, senior lecturer, Perm National Research Polytechnic University.

Grigory P. Khizhnyak, Dr. Sc., associate professor, head of the department of oil and gas technologies, Perm National Research Polytechnic University.

Vladislav I. Galkin, Dr. Sc., professor, head of the department of oil and gas geology, Perm National Research Polytechnic University. 